\title{
Gut bacterial communities across tadpole ecomorphs in two diverse tropical anuran faunas
}

\author{
Miguel Vences $^{1}$ - Mariana L. Lyra ${ }^{2}$. Jordan G. Kueneman ${ }^{3}$ • Molly C. Bletz ${ }^{1}$. \\ Holly M. Archer ${ }^{3}$. Julia Canitz ${ }^{1,4}$ • Svenja Handreck ${ }^{1,5}$ • Roger-Daniel Randrianiaina ${ }^{6}$. \\ Ulrich Struck $^{7} \cdot$ Sabin Bhuju ${ }^{8} \cdot$ Michael Jarek $^{8} \cdot$ Robert Geffers $^{8}$. \\ Valerie J. McKenzie $^{3}$ - Christoph C. Tebbe ${ }^{9}$ Célio F. B. Haddad ${ }^{2} \cdot$ Julian Glos $^{10}$
}

Received: 9 December 2015 /Revised: 8 February 2016 / Accepted: 12 February 2016 /Published online: 29 February 2016

(C) Springer-Verlag Berlin Heidelberg 2016

\begin{abstract}
Animal-associated microbial communities can play major roles in the physiology, development, ecology, and evolution of their hosts, but the study of their diversity has yet focused on a limited number of host species. In this study, we used high-throughput sequencing of partial sequences of the bacterial 16S rRNA gene to assess the diversity of the gutinhabiting bacterial communities of 212 specimens of tropical anuran amphibians from Brazil and Madagascar. The core gut-associated bacterial communities among tadpoles from two different continents strongly overlapped, with eight highly represented operational taxonomic units (OTUs) in common. In contrast, the core communities of adults and tadpoles from Brazil were less similar with only one shared OTU. This suggests a community turnover at metamorphosis. Bacterial diversity was higher in tadpoles compared to adults. Distinct differences in composition and diversity occurred among gut
\end{abstract}

Communicated by: Sven Thatje

Electronic supplementary material The online version of this article (doi:10.1007/s00114-016-1348-1) contains supplementary material, which is available to authorized users.

Miguel Vences

m.vences@tu-braunschweig.de

1 Zoological Institute, Technische Universität Braunschweig, Mendelssohnstr. 4, 38106 Braunschweig, Germany

2 Departamento de Zoologia, Instituto de Biociências, UNESP - Univ Estadual Paulista, Campus Rio Claro, Av 24A, N 1515, CEP 13506-900 Rio Claro, SP, Brazil

3 Department of Ecology and Evolutionary Biology, University of Colorado, Ramaley N-122, UCB 334, Boulder, CO 80309, USA

4 Evolutionary Biology and Special Zoology, Institute for Biochemistry and Biology, University of Potsdam, Karl-Liebknecht-Str. 24-25, 14476 Potsdam, Germany bacterial communities of conspecific tadpoles from different water bodies and after experimental fasting for 8 days, demonstrating the influence of both environmental factors and food on the community structure. Communities from syntopic tadpoles clustered by host species both in Madagascar and Brazil, and the Malagasy tadpoles also had species-specific isotope signatures. We recommend future studies to analyze the turnover of anuran gut bacterial communities at metamorphosis, compare the tadpole core communities with those of other aquatic organisms, and assess the possible function of the gut microbiota as a reservoir for protective bacteria on the amphibian skin.

Keywords Amphibia $\cdot$ Anura $\cdot$ Tadpoles $\cdot$ Gut microbiota . 16SrRNA $\cdot$ Stableisotopes
5 Visualization Group, Otto-von-Guericke University, Magdeburg, Germany

6 Département de Biologie Animale, Université d'Antananarivo, 101 Antananarivo, Madagascar

7 Museum für Naturkunde, Leibniz-Institut für Evolutions- und Biodiversitätsforschung, Invalidenstrasse 43, 10115 Berlin, Germany

8 Department of Genome Analytics, Helmholtz Centre for Infection Research, Braunschweig, Germany

9 Thünen Institute of Biodiversity, Bundesallee 50, 38116 Braunschweig, Germany

10 Department of Animal Ecology and Conservation, University of Hamburg, Martin-Luther-King Platz 3, 20146 Hamburg, Germany 


\section{Introduction}

Anuran amphibians are characterized by a highly distinctive larval stage, the tadpole (Altig and McDiarmid 1999). Tadpoles are characterized by a whole set of unique morphological features of which many are related to feeding, such as the unique keratinized jaw sheaths and labial teeth of the oral disk. Metamorphosis of anurans does not only consist of reduction of tail and gills and appearance of limbs and lungs, but it also involves a profound modification of bauplan components related to feeding (Bjorndal 1997; Viertel and Richter 1999) as they transition from an omnivorous suspension feeder (Altig and McDiarmid 1999) to an exclusively carnivorous adult.

Although the trophic ecology of tadpoles has been approached by numerous gut content studies, it still is not clear what tadpoles really eat (Altig et al. 2007), i.e., which of the ingested matter they actually digest and what position they occupy in the food chain. Anurans have evolved a spectacular diversity of tadpole morphology and ecology, including open-water filter feeding with largely reduced keratinized oral disk structures, sucker-mouthed larvae with large numbers of papillae and labial tooth rows for better adherence to rocks in fast-flowing streams, funnel-mouthed surface feeders, and numerous other highly specialized forms (Altig and Johnston 1989). However, comparative and integrative studies on the trophic ecology of these ecomorphological guilds of anuran larvae are exceedingly rare (Inger 1986; Rossa-Ferres et al. 2004; Verburg et al. 2007; Arribas et al. 2015), and research on tadpole nutritional ecology is still lacking (Pryor 2014). While tadpoles often are seen as herbivorous, they readily ingest and benefit from animal material in terms of survival and growth, and microorganisms have often been found to represent an important part of their diet (Whiles et al. 2006). Verburg et al. (2007) found clear differences in isotopic signatures between trophic groups of tadpoles and distinguished microbial feeders, herbivores, and neuston feeders. Such differences predict physiological adaptations to digest different kinds of food, but comparative analyses of intestinal morphology, physiology, and symbiotic intestinal (gut) microbiota are lacking for tadpoles.

The rapid rise of increasingly efficient DNA sequencing techniques during the past two decades has led to massive advances in numerous fields of biology. A noteworthy finding was the recognition of the astonishing diversity and ubiquity of microorganisms, especially bacteria and archaea, and their influence on eukaryotic life (McFall-Ngai et al. 2013). Hostassociated microbial communities (microbiota) and their joint genomes (microbiomes) are now known to play major roles in the physiology, development, ecology, and evolution of their hosts, with an emerging understanding that they contribute to a healthy immune system and metabolism (Tuddenham and Sears 2015; Palm et al. 2015).
While a wealth of studies have focused on the composition of the human gut microbiome (e.g., Arumugam et al. 2011), research in amphibians has mostly dealt with the microbial communities on the skin, particularly in the context of elucidating interactions between bacteria and the skin-associated fungal pathogen Batrachochytrium dendrobatidis (Harris et al. 2006, 2009; Woodhams et al. 2007; Lauer et al. 2007, 2008; Brucker et al. 2008; Becker et al. 2009; Becker and Harris 2010; Loudon et al. 2014; Jani and Briggs 2014). Studies have shown that the amphibian skin microbial communities are diverse and variable, with Proteobacteria making up a large proportion of bacterial taxa and with differences between syntopic amphibian species, their locations, and developmental stages (McKenzie et al. 2012; Kueneman et al. 2014, 2016; Belden et al. 2015).

Pioneering efforts to characterize bacterial diversity from the gut of amphibians were published by Bjorndal and Pryor (2005), Bjorndal (1997), and Pryor (2008). More recently, a study of Kohl et al. (2013) and a review by Colombo et al. (2015) compared the amphibian gut microbiota with that of other vertebrates. The mammalian gut microbial communities differ in composition from other animals (Ley et al. 2008b), but they also show similarities to those of other amniotes by being composed predominantly of Firmicutes (mainly represented by Clostridia) and Bacteroidetes. The gut microbiota of fish, however, contains mainly Proteobacteria and Fusobacteria (Colombo et al. 2015). A recent comparison of the gut microbiomes of larval and adult leopard frogs (Kohl et al. 2013) found that the bacterial communities of tadpoles were similar to those of fish while the adult communities were more similar to those of amniotes.

In this study, we report on the bacterial diversity of the gut microbiome of anuran communities from Brazil and Madagascar. We used high-throughput sequencing of a part of the bacterial 16S ribosomal RNA (rRNA) gene, PCR amplified from total DNA directly extracted from gut material. This method enables observation of the total bacterial community independent of their culturability on laboratory growth media, thus giving a more realistic view on bacterial species richness and diversity. We address several questions of relevance for anuran ecology and evolution based on this approach. (1) We first ask whether tadpoles of tropical frogs have gut bacterial communities differing from adults, as could be expected from previous studies on single species (Kohl et al. 2013) and from the radically different diets of larvae versus adults. (2) We extend the comparison to tadpoles from different continents (Madagascar vs. Brazil) to assess possible similarities in bacterial communities among these geographically and taxonomically distant amphibian larvae. (3) We then compare the gut bacterial communities of co-occurring tadpoles from streams in Madagascar and ponds in Brazil, to better understand the extent of species-specific differences as they are known from bacterial communities from the skin of 
different amphibian species (McKenzie et al. 2012). We also integrate the $16 \mathrm{~S}$ data with stable isotope signatures and diet analyses of the Madagascan tadpole assemblage to obtain first insights into potential influences of diet composition and diversity on the gut bacterial communities. (4) Furthermore, we report the results of a multispecies tadpole fasting experiment to illuminate the dynamics of gut bacteriome composition and to assess the importance of ingested bacteria versus resident gut bacteria in the $16 \mathrm{~S}$-determined communities.

On the basis of the analytical snapshots reported in this study, we highlight several major unanswered questions and suggest future research activity of paramount importance. We conclude that composition and diversity of gut microbiomes of larval and adult frogs constitute a highly understudied field, and the elucidation of their structural and functional diversity is crucial to understand amphibian evolution, ecology, and conservation.

\section{Materials and methods}

\section{Gut and skin microbiota in adult and tadpole stages of Brazilian frogs}

Fieldwork was carried out in April 2015 at three locations in Brazil: (1) Itapé, Rio Claro municipality, São Paulo state $(22.32618 \mathrm{~S}, 47.712576 \mathrm{~W})$, which is in a transition region between Atlantic forest and Brazilian savanna; (2) a stream near Picinguaba, Ubatuba municipality, São Paulo state (23.365265 S, 44.800907 W); and (3) Itagua, Ubatuba municipality, São Paulo state (23.457134 S, 45.051457 W), at the edge of the town of Ubatuba on the coast, not far from site 2, both in the Atlantic forest. Both Rio Claro and Ubatuba municipalities have very diverse anurans assemblages with about 30 species (Zina et al. 2007) and 55 species (CFBH, unpublished data) known to occur at these locations, respectively. Tadpoles and adults were collected opportunistically on 12 and 23 April 2015. Tadpoles were captured during the day using dip nets and adults were hand captured during night searches. Tadpoles were taken to the lab in water from the original water bodies and further processed within $12 \mathrm{~h}$ upon capture. We processed each tadpole with gloved hands as follows: (1) rinsed with about $20 \mathrm{ml}$ of filtered and autoclaved, double-distilled water; (2) swabbed for skin microbiota analysis (using sterile MW113 swabs of Medical Wire \& Equipment, Corsham, UK); (3) euthanized by MS-222 overdose; and (4) dissected with new autoclaved scissors and tweezers to obtain intestinal tract samples. Samples containing a large portion of the midgut (which makes up the largest part of the intestinal tract in carnivorous tadpoles; Toloza and Diamond 1990; Bloom et al. 2013) were stored in separate sterile microcentrifuge vials and immediately frozen.
We collected tadpoles from different ponds in Itapé, most of which were immediately sampled. To understand shortterm variation of gut bacterial communities after fasting, a subset of specimens were brought alive into the lab and kept for 8 days without food in nutrient-poor mineral water at about $22^{\circ} \mathrm{C}$ water temperature. The water was changed every 2 days to remove feces and avoid coprophagy. Subsequently, specimens were processed in the same manner described previously for wild individuals.

DNA from gut samples was extracted using MoBio Power Soil extraction kits (MoBio Laboratories, Carlsbad, CA, USA) with minor adjustments outlined in Kueneman et al. (2014). The dual index approach of Kozich et al. (2013) was applied to PCR amplify and subsequently sequence the V4 region (Brosius et al. 1981) of the bacterial 16S rRNA gene. For PCR amplification, both the forward and reverse primers included the Illumina adapter and a unique barcode tag. This approach allows obtaining 576 PCR products with unique barcode combinations by using 24 uniquely barcoded versions of the forward primer $515 \mathrm{~F} \mathrm{com}$ bined with 24 unique versions of the reverse primer $806 \mathrm{R}$ (details in Supplementary information). To confirm the identity of the sampled tadpoles, we sequenced a fragment of the large mitochondrial ribosomal subunit gene (mt-16S rRNA; details in Supplementary information).

\section{Gut microbiota across Malagasy tadpole ecomorphs}

Samples from mantellid tadpoles in Madagascar were available from various streams close to or within Ranomafana National Park, which is a hyperdiverse area with over 100 amphibian species (see Strauß et al. 2010, 2013). For analysis of gut microbiota, we focused on a large stream $(21.24828 \mathrm{~S}$, 47.42948 E) near Ambatolahy village that harbors an anuran community with diverse tadpole ecomorphs. In addition, we included a few samples of different ecomorphs from a nearby stream, located close to Valbio biological station $(21.25318 \mathrm{~S}$, 47.42118 E). These tadpoles were collected in July 2009 and euthanized by MS-222 overdose, and their intestines were removed immediately and preserved in pure ethanol. Tadpoles were identified morphologically based on previous surveys that included an intensive DNA barcoding program (Strauß et al. 2013). Both gut microbiota and food items were determined from these samples. We compared the gut microbiota of four tadpole ecomorphs: Boophis reticulatus (generalized stream tadpole), Boophis marojezensis (rapid-adapted suctorial tadpole), Boophis narinsi (tadpole with reduction of keratinized structures in oral disk), and species of Mantidactylus (subgenus Chonomantis; funnel-mouthed tadpoles). Tadpoles of several syntopic species of Chonomantis are morphologically indistinguishable (Grosjean et al. 2011a) and therefore were pooled for analysis; most samples analyzed here are likely assignable to Mantidactylus melanopleura and 
Mantidactylus opiparis. Tadpoles of B. marojezensis, $B$. narinsi, and Chonomantis were collected at Ambatolahy, whereas $B$. reticulatus were collected at Valbio. A series of additional tadpoles from the same streams was collected in December 2014, immediately sacrificed, and dissected, and gut material frozen upon collection; these were included only in the overall comparisons between Brazilian and Madagascan tadpoles.

Gut material of Malagasy tadpoles collected in 2009 was analyzed for bacterial diversity by the same protocol as the Brazilian samples, with only minor modifications. More specifically, DNA was extracted using the 96-well MoBio Power Soil Extraction kit as per the manufacturer's protocol with the adjustments outlined in Kueneman et al. (2014) to increase DNA yield. In addition, centrifuge times were doubled in length to account for the reduced rotor speed available. Sequencing of these samples took place at the Department of Genome Analytics of the Helmholtz Center for Infection Biology in Braunschweig. Gut material of the set of tadpole samples collected in 2014 was analyzed using a slightly different protocol. DNA extraction in these samples was completed with the same method; however, $2 \times 150$ Illumina MiSeq sequencing was completed with single index primers as in Kueneman et al. (2014).

\section{Sequence analysis}

All sequence processing was conducted using Quantitative Insights Into Microbial Ecology software (MacQIIME v1.9.1) unless otherwise stated (Caporaso et al. 2010). All samples from Brazil and Madagascar were processed together for joining reads, quality filtering, and picking operational taxonomic units (OTUs). Paired-end reads from each sample were joined using Fastq-join with default settings (Aronesty 2011, 2013). Sequences were quality filtered to remove low-quality sequences with the following criteria: any ambiguous base calls, less than $75 \%$ of read had consecutive base call with a quality score greater than 5 , and more than 3 consecutive low-quality base calls. Additionally, sequences were further filtered by read length to include only the sequences between 250 and 253 bp using the usegalaxy.org website.

UCLUST (Edgar 2010) was used to de novo cluster the sequences into OTUs at $97 \%$ sequence identity. The most abundant sequence was selected as a representative sequence from each OTU. These representative sequences were aligned to the Greengenes (version 13.8) reference alignment using PyNAST (Caporaso et al. 2010) and taxonomy was assigned using the RDP classifier (Wang et al. 2007) with an $80 \%$ confidence threshold. A phylogenetic tree was built with FastTree (Price et al. 2010) adhering to QIIME's standard procedures. OTUs with less than $0.005 \%$ of the total reads were filtered out as per the recommendations of Bokulich et al. (2013). After all quality filtering, 5,702,134 reads remained. The Brazil datasets (adult and tadpole gut samples and tadpole skin samples) had on average 6988,9256 , and 4616 sequences per sample, with maxima of 24,587, 66,548, and 15,933 sequences. The Madagascar tadpole gut samples had on average 22,942 sequences with a maximum of 92,684, mostly caused by high numbers in the samples collected in 2014 which were combined with fewer samples in one sequencing run (details in Supplementary Table S8). All samples were rarefied to 1000 sequences per sample to standardize the number of reads across samples for further analyses. Samples with fewer than 1000 sequences were removed from further analysis. See Table 1 for an overview of sample sizes and numbers of sequences for different subsets of data used in the various analyses.

Sets of high-throughput amplicon reads can contain chimeric sequences that form during PCR, mainly as a result of incomplete extension during the PCR cycle due to inadequate time or when an undenatured region or secondary structure in the templates hinders the DNA polymerase from continuing (Qiu et al. 2001). In this study, we ran our main analyses without attempting to remove such chimeric sequences because we were concerned about accidentally removing crucial and real OTUs by applying chimera detection algorithms. In fact, the performance of chimera detection algorithms degrades with read length, and with short $250 \mathrm{bp}$ reads, it is more difficult to tell whether a sequence is chimeric or not with confidence, as compared to longer sequences. Furthermore, chimera formation is reduced when sequencing shorter fragments and only one variable region (V4 in the present study) because extension is more likely to be completed in such cases. Because chimeras are expected to be comparatively rare and because we have also implemented a filtering step (according to Bokulich et al. 2013) removing OTUs with

Table 1 Number of samples and reads of different datasets used in the analyses herein (not considering controls): (1) comparison of amphibianassociated communities of gut and skin in adults and tadpoles (as shown in Fig. 1); (2) comparison of tadpole gut microbial communities in two ponds from Itapé, Rio Claro, São Paulo, Brazil; (3) microbial community structure of wild versus fasted Brazilian tadpoles; and (4) microbial community structure of distinct tadpole ecomorphs of Malagasy amphibians. Note that datasets 2 and 4 are subsets of dataset 1 , while dataset 3 contains an additional 18 samples (fasted tadpoles) that were not included in dataset 1

\begin{tabular}{llllll}
\hline & \multicolumn{2}{l}{$\begin{array}{l}\text { No. of total samples } \\
\text { (pre/postfiltering) }\end{array}$} & & \multicolumn{2}{l}{$\begin{array}{l}\text { No. of reads } \\
\text { (pre/postfiltering) }\end{array}$} \\
\cline { 2 - 3 } \cline { 5 - 6 } & Prefiltering & Postfiltering & & Prefiltering & Postfiltering \\
\hline 1 & 276 & 229 & & $6,271,344$ & $5,136,966$ \\
2 & 18 & 16 & & 206,267 & 128,649 \\
3 & 37 & 35 & & 429,030 & 316,577 \\
4 & 25 & 24 & 248,466 & 192,332 \\
\hline
\end{tabular}


fewer sequences than $0.005 \%$ of the total reads, we assumed that the impact of possible remaining chimeras on our analysis would be negligible. Furthermore, we performed additional analyses to evaluate the impact of chimera removal on our data. Chimera removal was conducted on a per sample basis using usearch61 de novo based detection within QIIME (http://drive5.com/usearch/usearch docs. html; Edgar et al. 2011). The detected chimeric sequences were subsequently removed from the qualityfiltered FASTA file prior to OTU selection. OTUs were defined as outlined above and selected analyses repeated with this dataset. Despite minor differences, the results after chimera removal coincided largely with the ones presented hereafter in the main paper (see Supplementary information). Diversity values were slightly lower after chimera removal, but differences among data categories remained similar (Supplementary Information).

Alpha diversity metrics, including Chao 1 and the number of observed OTUs, were calculated within QIIME for all samples (total number of amphibian gut samples and skin swabs $=230$ ). To evaluate the influence of host species and site on Brazilian tadpole gut microbiota, beta diversity was calculated using the weighted and unweighted UniFrac metric within QIIME (Lozupone and Knight 2005). These matrices were analyzed further in Primer 7 by visualizing this matrix with a principal coordinates analysis ( $\mathrm{PCoA}$ ) and performing a permutational multivariate analysis of variance (PERMANOVA) to statistically analyze the influence of host species and site. To compare the microbial communities of distinct tadpole ecomorphs of Malagasy tadpoles, beta diversity was calculated as described above. Within Primer 7, a PERMANOVA was performed to analyze the influence of host species/ecomorph, and PCoA was used to visualize the beta diversity matrix. In addition, pairwise PERMANOVAs were completed to further investigate the host species effect seen with the Malagasy tadpole ecomorph dataset. To more closely investigate the OTUs that were driving the patterns observed between wild versus fasted Brazilian tadpoles and that of the Malagasy tadpole ecomorph comparison, we performed LefSe (Segata et al. 2011). In brief, this analysis considers the relative abundance of OTUs and statistically determines which OTUs are differentially abundant in the useddefined categories. Using the Galaxy web-based interface (http://huttenhower.sph.harvard.edu/galaxy/), modified output tables were uploaded with class-level microbial taxonomy for LefSe analysis. The default parameters (alpha $=$ 0.05 and least discriminate score $>2$ ) were used. The core bacterial community was determined and analyzed using QIIME. OTUs that were shared by $50 \%$ of the samples per category were included in the comparisons represented by Venn diagrams, generated as provided by Oliveros (2015) and subsequently adjusted graphically in CorelDraw X3 (Corel Corp.).

\section{Food and food chain position of Malagasy tadpole ecomorphs}

Analysis of food items was done manually using a microscope, from the same individual tadpoles that were also used for determining gut microbiota. In addition to the four species mentioned above, Boophis picturatus and Boophis majori were included. B. picturatus has enigmatic tadpoles without keratinized mouthparts that appear to ingest mainly sand (Altig and McDiarmid 2006; Grosjean et al. 2011b), and B. majori is the sister species of $B$. narinsi but differs distinctly in tadpole mouthparts (Vences et al. 2012). We used $1 \mathrm{~mm}^{3}$ of the anterior gut and dissolved the contained particles in $30 \mu \mathrm{l}$ of distilled water. The gut tissue was removed from each sample. Each sample was then vortexed, spread across a microscope slide, and analyzed at $\times 100$ magnification. All particles were counted by size class (using an ocular micrometer or the software AxioVision, Zeiss) and by major food type. Basic statistical comparisons were carried out in Statistica 7.1 (StatSoft Inc., Tulsa, USA).

In addition, samples taken from the same streams in January 2008 were available for analysis of stable isotopes. In each stream, a 30-m section was sampled using dip nets. Dip nets of different sizes and materials were used to obtain optimal sampling results for each stream. Depending on stream width, a varying number of persons started sampling at the downstream end of the study site and proceeded slowly upstream. Captured tadpoles were transported to the laboratory and then euthanized by a MS-222 overdose. A tissue sample from the tail muscle including the skin was taken from each specimen for stable isotope analysis $(\mathrm{C}$ and $\mathrm{N})$ and dried for $48 \mathrm{~h}$ in a drying oven. The amphibian specimens were identified by DNA barcoding based on a fragment of the mitochondrial 16S rRNA gene (Strauß et al. 2010, 2013).

Analysis of stable isotopes was carried out on the same species studied for food and microbiota (B. marojezensis, $B$. narinsi, $B$. reticulatus, four species of Chonomantis) and three additional species of Boophis with unique mouthparts that were not included in the microbiota analysis (Boophis elenae, $B$ majori, and B. picturatus). All tadpole tissue samples were tested individually for their isotope signatures at the Museum für Naturkunde in Berlin. Stable isotope analysis and concentration measurements of nitrogen and carbon were performed simultaneously with a Thermo/Finnigan MAT V isotope ratio mass spectrometer, coupled to a Thermo FlashEA 1112 elemental analyzer via a Thermo/Finnigan ConFlo III Interface. Stable isotope ratios $\left({ }^{15} \mathrm{~N} /{ }^{14} \mathrm{~N}\right.$ and $\left.{ }^{13} \mathrm{C} /{ }^{12} \mathrm{C}\right)$ are expressed in the conventional delta notation $\left(\delta^{15} \mathrm{~N}\right.$ and $\left.\delta^{13} \mathrm{C}\right)$ relative to atmospheric nitrogen and VPDB (Vienna PeeDee Belemnite standard). Standard deviation for repeated measurements of lab standard material (peptone) is generally below 0.15 per mill (\%) for nitrogen and carbon, respectively. Standard deviations of concentration measurements of 
replicates of our lab standard are $<3 \%$ of the concentration analyzed.

For each species, $\delta^{15} \mathrm{~N}$ and $\delta^{13} \mathrm{C}$ values were pooled and averaged from a different number of individuals (range 3 to 27) and from a different number of streams (1 to 7). Combining these two isotope signatures serves to determine the trophic niche of an animal (Layman et al. 2007a, b), although relating the isotope ratios to detailed food sources is more complex. In general, $\delta{ }^{15} \mathrm{~N}$ differences between species indicate divergent trophic position within a food web, and $\delta^{13} \mathrm{C}$ differences indicate a different use of major energy sources (DeNiro and Epstein 1981; Peterson and Fry 1987; Post 2002).

\section{Data accessibility}

Sequences of all barcoded specimens were deposited in GenBank (accession numbers KU517237-KU517364). The sequences of the amplicon libraries were deposited in the NCBI short read database (SRA accession SRP069304).

\section{Results}

\section{Gut microbiota in tadpole and adult stages of Brazilian frogs}

Overall, the diversity of tadpole gut bacteria averaged over 79 specimens from 12 species collected in Brazil (Fig. 1) revealed a diverse community structure, dominated by members of the phyla Firmicutes (27.1\%; mostly Clostridia), Synergistetes (17.5\%; mostly Synergistia), and Proteobacteria (15.8\%; with similar proportions of Beta-, Gamma-, and Deltaproteobacteria and a lower contribution of Alphaproteobacteria). The bacterial community of adults from the same collecting sites and largely of the same frog species (24 individuals of 10 species) differed; while the Firmicutes $(30.4 \%)$ and Proteobacteria $(17.8 \%)$ were equally abundant, these communities exhibited a higher proportion of Verrucomicrobia $(22.4 \%$; mostly Verrucomicrobiae) and Deferribacteres (13.7 \%) and a lower proportion of Synergistetes (2.9\%) (Fig. 1). The diversity of gut bacterial communities of the tadpoles was more than double that of adults, as seen by richness (number of OTUs per sample) and Chao1 indices (Fig. 1).

For a subset of 24 tadpoles from seven species, we also analyzed the skin bacterial communities, in order to test for specificity of the communities present in the gut. Strong differences were revealed between skin and gut as habitats, the first dominated by Proteobacteria $(90.0 \%$; vast majority Betaproteobacteria). A more in-depth comparison was carried out for samples of the Physalaemus cuvieri tadpoles, which all were collected simultaneously at the same pond in Itapé, Rio
Claro, Brazil, and had gut and skin samples available from the same individuals. An analysis of this dataset (Fig. 1c) showed that overall, about $53 \%$ of the skin bacteria were also found in the gut, but in the gut, these shared OTUs made up only a small proportion $(13 \%)$ of the more diverse bacterial gut community. Comparing the skin versus gut core communities showed only two shared OTUs (Fig. 1f), representing $2 \%$ of the gut core community and $10 \%$ of the skin core community.

\section{Comparison of gut microbiota between continents}

The gut bacterial communities of tadpoles collected from rainforest streams in Ranomafana National Park in 2009 and 2014, including 109 specimens and based on their 16S rRNA sequence profiles, were remarkably similar to those of the Brazilian tadpoles (Fig. 1). Most OTUs could be assigned to the same phyla as were dominant in the Brazilian tadpoles: Firmicutes $(23.0 \%)$, Proteobacteria $(29.7 \%$, a higher proportion compared to Brazil), and Synergistetes (12.2\%). Also, bacteria of Bacteroidetes (8.7\%) and Planctomycetes $(8.9 \%)$ were relatively common. The alpha diversity was even higher than in the samples from Brazil, with an average of 100 OTUs and a Chaol index of 350 per sample (vs. 203 in the Brazilian tadpoles).

To understand whether certain bacterial community members regularly occur in tadpoles of different species and geographic regions, we determined which bacterial OTUs, if any, were shared among categories of samples. In fact, a first comparison between tadpoles from different continents revealed that 619 OTUs were shared, indicating that a high proportion of bacterial OTUs were present in tadpoles from disparate regions. We used the limited number of skin bacterial community samples of Brazilian tadpoles as a control (Fig. 1b) to understand if these shared bacteria were universally present in the samples analyzed. However, from the perspective of Brazilian gut communities, a high proportion of OTUs still was shared exclusively with Malagasy gut communities (570 OTUs, making up $70 \%$ of the entire set of OTUs found in the Brazilian tadpole gut samples).

Core community analysis at the $50 \%$ level (i.e., OTUs present in half of the samples of the respective category) revealed a core of 21 OTUs in the gut of Brazilian tadpoles and 49 OTUs in the gut of the Malagasy tadpoles. Eight of these OTUs were shared between Brazilian and Malagasy samples (Fig. 1d), and all of these were rather frequent, ranking 1-32 among all OTUs by number of reads (see Supplementary Table S5). Applying the same comparison to the core gut communities of tadpoles versus adults from Brazil revealed that only a single OTU was shared among these two core communities (Fig. 1e).

A closer look at the shared core community members revealed that the eight OTUs shared among Brazilian and Malagasy tadpole gut cores included one chloroplast-like 
Fig. 1 a Composition of gut and skin microbiota of Brazilian and Malagasy anurans, at the phylum level. All samples were rarefied at 1000 reads per sample. Numbers above columns show the number of samples analyzed, the average number ( \pm standard deviation) of bacterial OTUs per sample, and the average Chao 1 diversity index per sample. Skin samples were from a subset of the same tadpoles also analyzed for gut contents.

Note the dominance of

Proteobacteria in skin microbiota and the high diversity in tadpole gut microbiota. b-f Venn diagrams showing the number of bacterial OTUs shared among different categories of samples analyzed. $\mathbf{b}, \mathbf{c}$ Total number of OTUs shared among tadpole gut and skin samples, d-f OTUs shared between previously calculated core communities for the respective sample categories
A
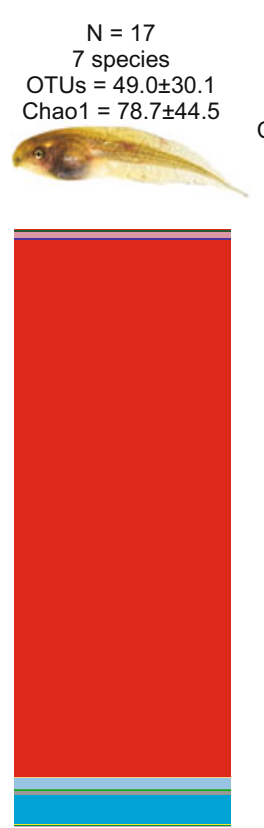

tadpole skin

(Brazil)
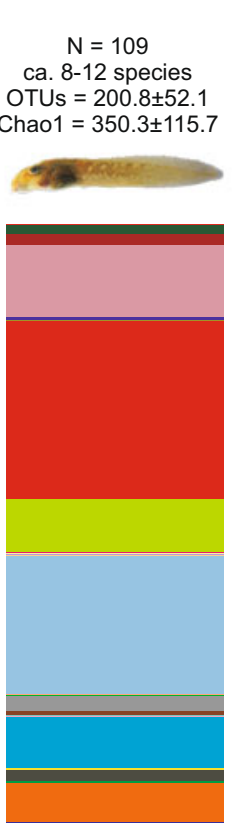

tadpole gut

(Madagascar)
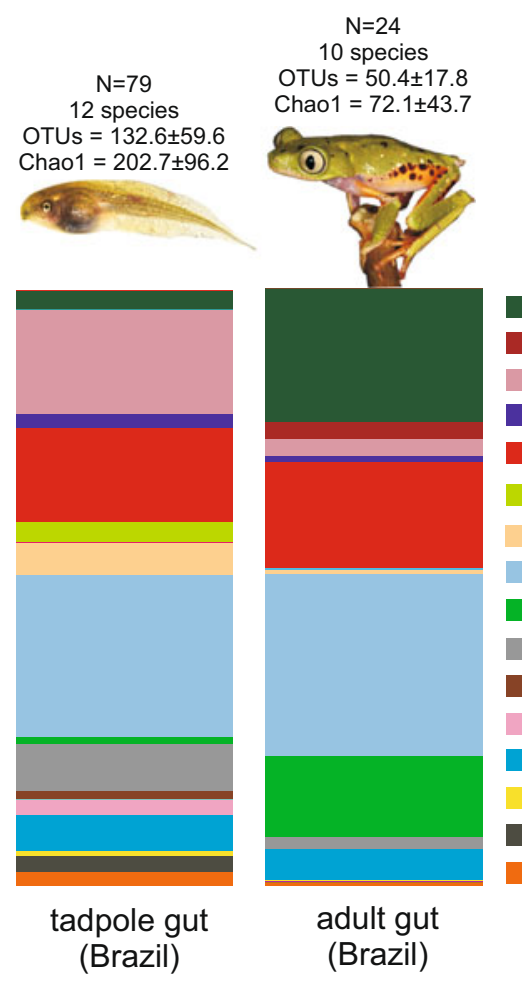

Verrucomicrobia

Tenericutes

Synergistetes

Spirochaetes

Proteobacteria

Planctomycetes

Fusobacteria

Firmicutes

Deferribacteres

Cyanobacteria

Chloroflexi

Chlamydiae

Bacteroidetes

Armatimonadetes

Actinobacteria

Other

adult gut

(Brazil)

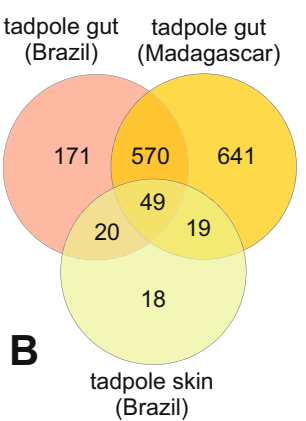

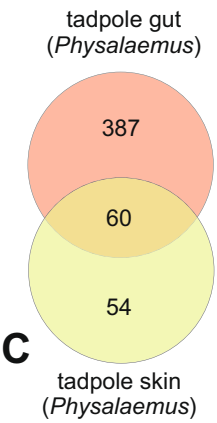
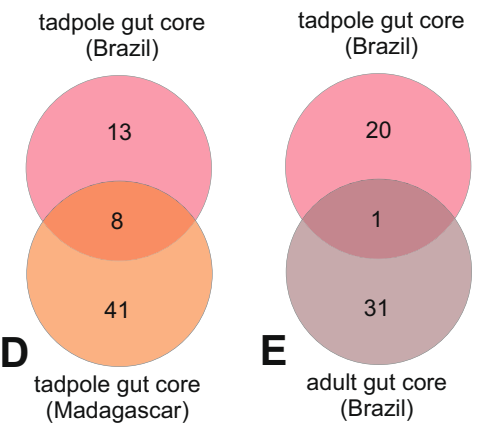

tadpole gut core (Physalaemus)

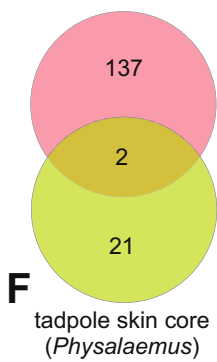

sample identified as Stramenopiles, and this OTU has been found previously in stream water samples (e.g., $100 \%$ BLAST hit with sequence KM376923). The remaining seven OTUs contained three Alphaproteobacteria widespread in soil and in aquatic sediments (one Bradyrhizobium and two Methylocystaceae, all showing in multiple cases complete sequence identity to sequences from a variety of environmental samples found in the GenBank database/entire nucleotide collection), one Firmicutes (Ruminococcaceae) previously found only in the gut of an Asian tadpole, and three OTUs (one Planctomycetes and two Synergistetes) not previously recorded but close (95-96 \% identity) to bacteria from insect gut communities (see Supplementary Table S5 for details). The single OTU shared among Brazilian tadpole and adult gut cores had $94 \%$ sequence identity with the respective gene from an unidentified Deltaproteobacterium of the family Desulfovibrionaceae (a group largely composed of sulfur-reducing, obligate anaerobic Proteobacteria).

\section{Gut microbiota variation among species, sites, and fasting tadpoles in Brazil}

At the site Itapé, two of four ponds harbored tadpoles of more than two anuran species each; therefore, a more detailed comparison was completed with all samples from these ponds. A plot of the first and second principal coordinates (PCo) calculated from unweighted UniFrac distances among the bacterial communities of each sample (Fig. 2) showed a clear influence of the host species. In pond 2, three specimens of two species of Hypsiboas clustered together and were distinct from two samples of Dendropsophus sanborni, the latter being closer to the environmental water control. In pond 4, eight out of nine samples of $P$. cuvieri clustered together and were distinct from two samples of $D$. sanborni, whereas the ninth $P$. cuvieri clustered close to the gut bacterial community of a fish collected from the same pond. The bacterial community structure differed significantly between host species and site (PERMANOVA, species: 


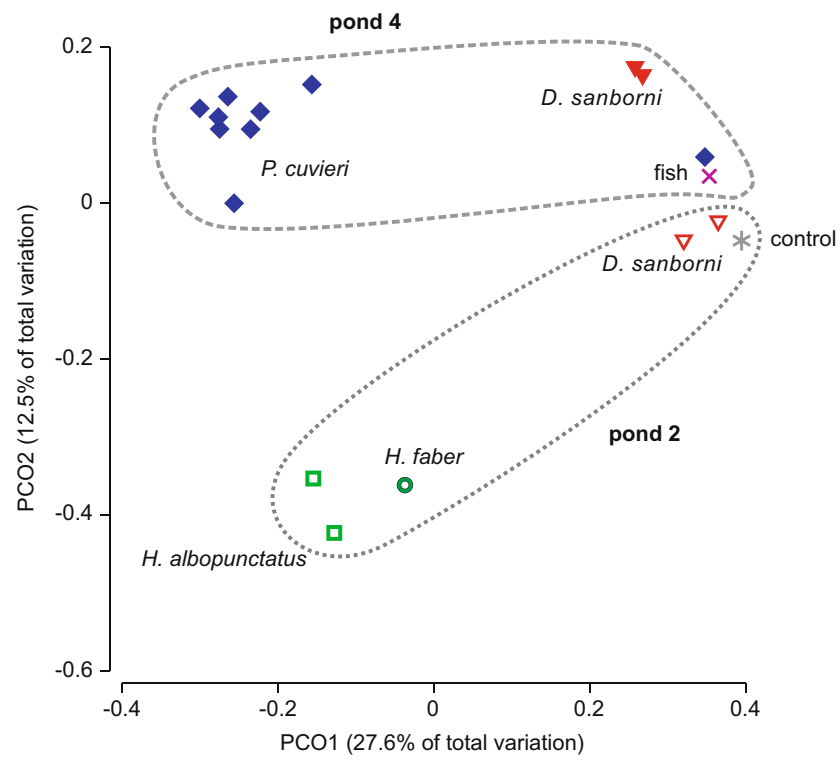

Fig. 2 Two-dimensional plot of principal coordinates analysis (unweighted Unifrac) showing differences in gut microbiota in tadpoles of four species of anurans from two ponds (named pond 2 and pond 4 and indicated by hashed lines) at Itapé, Rio Claro municipality, São Paulo, Brazil. All samples rarefied at 1000 reads. One fish (Astyanax paranae) from pond 4 and a sample of water from pond 2 were included as controls

pseudo- $F=2.996 ; P=0.001)$ although interactions between the two predictor variables could not be assessed because only one species was observed in the two ponds included in this analysis.

After 8 days of fasting and by superficial macroscopic examination, the dissected tadpole guts still contained darkcolored matter, suggesting that not all food had been entirely digested and excreted during the fasting period. The composition of the gut bacterial communities of Hypsiboas albopunctatus, Hypsiboas faber, and P. cuvieri drastically changed after fasting (Fig. 3). Weighted and unweighted UniFrac matrices revealed the same pattern (only the unweighted UniFrac matrix is presented in Fig. 3). In all three species, an increase in the proportion of the phylum Fusobacteria (from $0.0-0.1$ to $8.2-49.8 \%$ ) and a decrease in Firmicutes (from 22.4-39.7 to 13.4-20.2 \%) were obvious. Furthermore, in the two Hypsiboas, an increase in Verrucomicrobia (from 1.3-2.3 to 9.5-11.0\%) and a decrease in Synergistetes (from 26.3-30.8 to 1.1-11.5\%) were apparent, whereas in Physalaemus, Proteobacteria increased distinctly (from 15.4 to $46.4 \%$ ). Two species with tadpoles in the fasting regime but without wild-caught samples from the same ponds (Dendropsophus minutus and Scinax fuscovarius) showed a high proportion of Verrucomicrobia (51.6 and $42.7 \%$ ), presence of Fusobacteria (5.6 and $6.9 \%$ ), and low proportion of Firmicutes (2.8 and $11.4 \%$ ). Indeed, a LefSe analysis confirmed that Fusobacteria and Verrucomicrobia were specific for the fasted tadpole gut communities whereas Firmicutes and Acidobacteria were associated with gut communities of wild tadpoles (http://huttenhower.sph. harvard.edu/galaxy/; abs LDA scores $>2$ ).

Except for wild tadpoles of $D$. sanborni, which generally had low diversity values, both the richness (average number of OTUs) and the Chaol diversity index per sample were distinctly lower in fasting compared to nonfasting tadpoles (Fig. 3).

\section{Gut microbiota comparisons among selected Malagasy tadpole ecomorphs}

The four selected taxa (B. narinsi, B. marojezensis, B. reticulatus, and Chonomantis sp.) belong to highly distinct tadpole ecomorphs and showed distinct differences in their bacterial composition. Again, both weighted and unweighted UniFrac matrices revealed the same pattern. The bacterial communities in these tadpoles were dominated by OTUs of Bacteroidetes (species averages ranging from 20.9 to $69.2 \%$ ) and Proteobacteria (10.4-48.0\%), with a relatively low proportion of Firmicutes (5.1-9.0 \%). In a principal coordinates analysis (Fig. 4a), all samples of Chonomantis clustered apart from Boophis samples. The three Boophis species appeared to differ as well from each other, but two $B$. reticulatus and one B. marojezensis were in the same cluster as all B. narinsi. The differences between the four species were highly significant (PERMANOVA, pseudo- $F=6.955 ; P=0.001$ ); pairwise differences between Chonomantis and each of the three Boophis were also significant $(P<0.01)$, but differences between Boophis species were not.

\section{Food and food chain position of Malagasy tadpole ecomorphs}

In order to understand whether differences in gut bacterial communities corresponded with differences in ingested food and trophic niche, we studied gut content and stable isotopes from the Malagasy tadpoles. In all 25 gut samples examined, we found a large number of particles but could reliably identify only a small portion of these (about $5 \%$; Fig. 4d). The majority of gut content consisted of small $<1 \mu \mathrm{m}$ particles, probably suggesting that the tadpoles were mostly ingesting detritus and tiny inorganic (sand and loam) and organic particles. Mean particle size in micrometers ( \pm standard deviation) was $11.3 \pm 1.9$ for B. picturatus ( $n=5$ samples), $11.0 \pm 1.1$ for B. marojezensis $(n=4), 8.6 \pm 2.7$ for $B$. reticulatus $(n=8), 7.2$ \pm 1.9 for B. narinsi $(n=9)$, and $8.9 \pm 3.7$ for Chonomantis $(n=10)$. Of the identifiable particles, diatoms made up $87-99 \%$ in Chonomantis, B. reticulatus, and B. marojezensis, whereas in $B$. narinsi, we found numerous larger organic particles. Because the diatoms were much smaller than many other items identified, in an estimate of total volume, they remained dominant only in B. reticulatus and B. marojezensis with 68 and $99 \%$, whereas in Chonomantis, plants, algae, and fungi 
Fig. 3 Composition and diversity of gut microbiota of tadpoles of the genera Dendropsophus, Hypsiboas, Physalaemus, and Scinax, from individuals collected directly from the wild (left set of bars) and from other individuals collected simultaneously at the same site and kept for 8 days of fasting (right set of bars). All samples rarefied at 1000 reads per sample; number of OTUs and Chaol diversity index are given as average values per sample

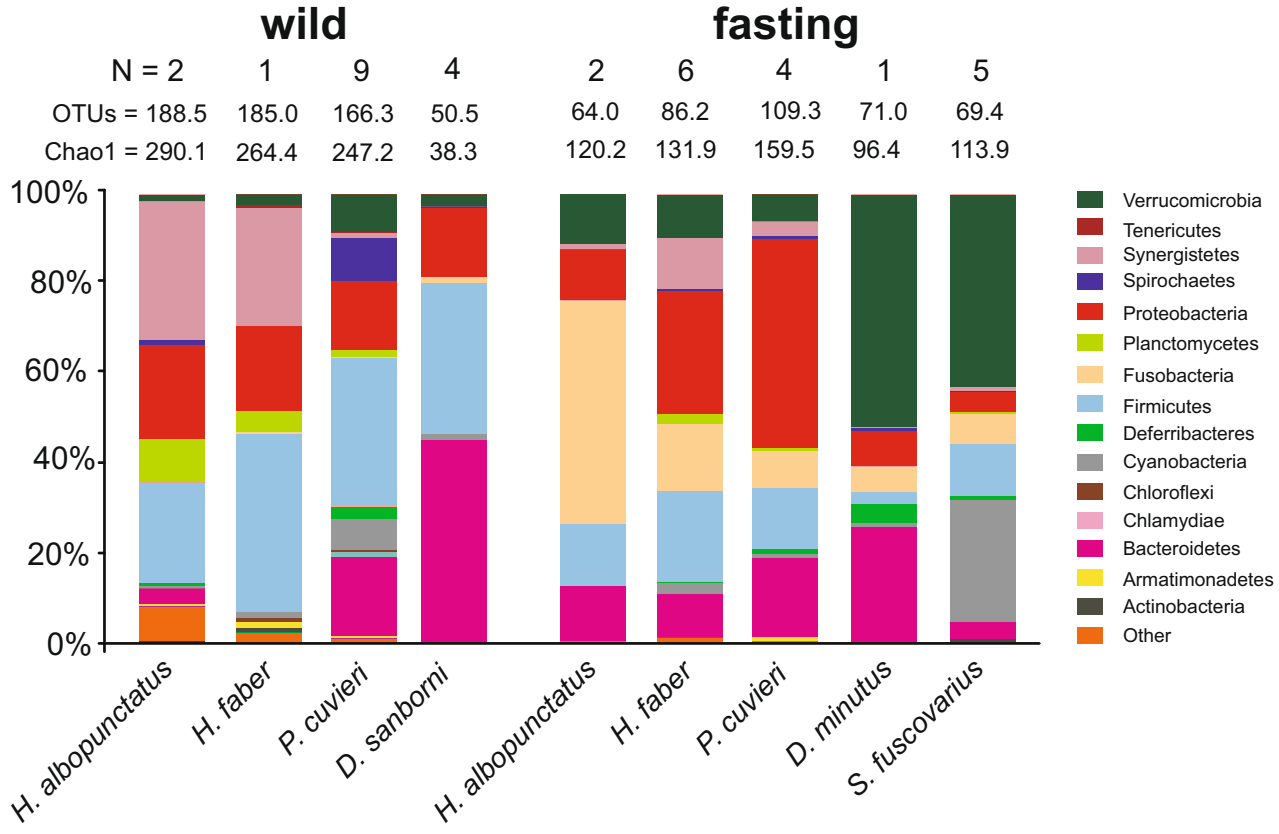

and parts of insects made up a larger proportion of the identifiable gut content.

Stable isotope data were collected from a set of tadpoles that were DNA barcoded and therefore all of them could be assigned reliably at the species level, including those of Chonomantis. A biplot of $\delta^{15} \mathrm{~N}$ and $\delta^{13} \mathrm{C}$ (Fig. 4c) displays a clear structure by species and (probably) by ecomorph for the 107 samples studied (original values in Supplementary materials). Based on visual inspection of the graph, the four species of Chonomantis which morphologically are extremely similar to each other (Grosjean et al. 2011a) were also similar in their $\delta^{13} \mathrm{C}$ and $\delta^{15} \mathrm{~N}$ values. B. reticulatus and $B$. marojezensis had values close to those of Chonomantis, whereas $B$. narinsi differed distinctly in having lower $\delta^{13} \mathrm{C}$ values.

Tadpoles of two morphologically unique species were included in the isotope study but not in the analysis of the gut microbiome. One of these, B. picturatus, had an average $\delta^{15} \mathrm{~N}$ of 6.65 and thus higher than all other tadpoles in the dataset. $B$. majori, the sister species of $B$. narinsi, had the second smallest $\delta^{13} \mathrm{C}$ values after $B$. narinsi but the lowest $\delta^{15} \mathrm{~N}$ values of all species (2.7).

\section{Discussion}

This study enhances our understanding of the richness and diversity of bacterial taxa inhabiting the amphibian gut, by revealing species-specific bacterial community patterns in tadpoles. Evidence was obtained for a shared core bacteriome across distinct geographic regions and for significant differences between larval and adult amphibian gut bacteriomes. Rather than providing a comprehensive understanding of the taxonomic and functional bacterial diversity, the snapshots herein allow us to formulate hypotheses and highlight promising fields for further research.

The results of this study revealed a striking overlap between geographically distinct tadpoles, and there was little overlap between bacterial communities from tadpoles and adult specimens. Overall, the gut bacteria from adults were distinctly less diverse than those from tadpoles. The diversity differences between tadpoles and adults agree with the results of Kohl et al. (2013) who observed a change in microbial community structure and diversity after metamorphosis in leopard frogs. Also the phylum-level composition of tadpole bacterial gut communities in our study roughly agrees with the previous findings (Kohl et al. 2013). Although our results and previous data (Kohl et al. 2013) agree in suggesting a shift in gut bacterial taxa across metamorphosis, more detailed analyses at a finer scale through metamorphosis would be needed to characterize this transition in more detail (e.g., whether bacteria are passed as initial colonizers of the adult gut). In addition, metagenomic approaches could be employed here as well to expand our understanding of this transition and explore the functional transition of the microbiome when their host transitions from this aquatic larval stage into a terrestrial or semiterrestrial adult (in most cases). This information could be linked with evaluating the impact of dietary preferences. Does the insectivorous nature of many adult anurans lead to a functional shift toward chitinolytic bacteria? Are these "less diverse" communities of adults also exhibiting less functional diversity? Or is functional diversity maintained simply by fewer taxa?

We demonstrated that at least some bacterial OTUs are shared between the skin and gut microbiota, which raises the 

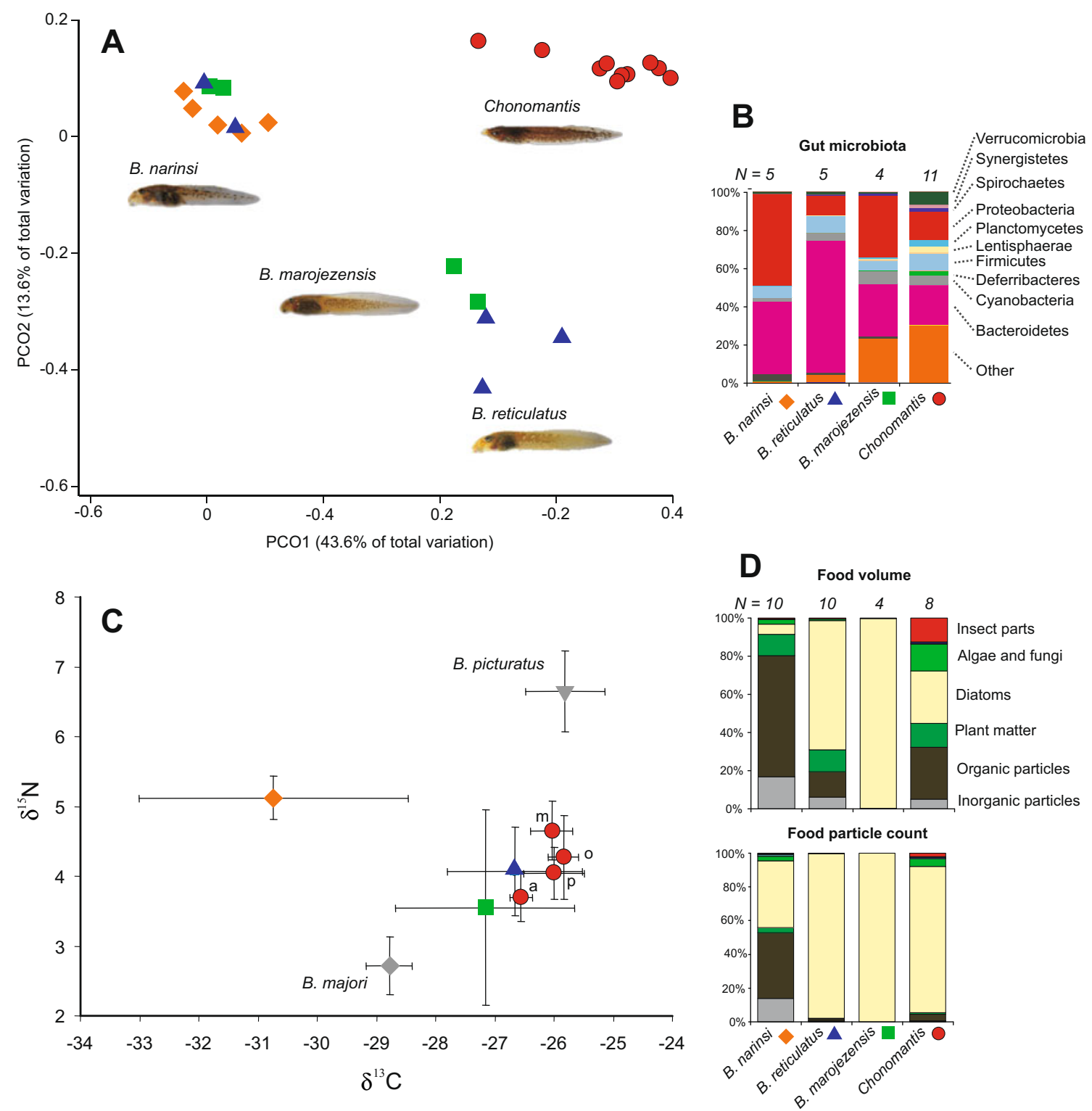

Fig. 4 Differences in gut microbiota, stable isotope signatures, and ingested food in tadpoles of the genera Boophis and Mantidactylus (subgenus Chonomantis) from Ranomafana National Park, Madagascar. Note that Chonomantis specimens in $\mathbf{a}, \mathbf{b}$, and $\mathbf{d}$ were not DNA barcoded and therefore might belong to different species. a Two-dimensional plot of principal coordinates analysis (unweighted UniFrac) of four species of tadpoles, showing separation of most individuals in distinct clusters. All samples rarefied at 1000 reads. b Composition of gut microbiota at the

phylum level (same data used in a). $\mathbf{c}$ Plot of average signatures of stable isotopes of carbon and nitrogen with standard deviation. Red symbols represent four different species of the subgenus Chonomantis, in the order of increasing $\delta^{15} \mathrm{~N}$ values: a, Mantidactylus aerumnalis; $p$, M. paidroa; $o$, M. opiparis; and $m, M$. melanopleura. d Composition of gut content of tadpoles, quantified as proportion of countable particles (lower barplot) and relative volume of particle categories. See Supplementary information for factors used to calculate volumes

question as to whether the gut acts as a reservoir from which such bacteria colonize or recolonize the skin (e.g., after shedding). Elucidating such relationships will be critical for understanding the skin microbial community dynamics, which is critical due to the role of these bacteria in protecting amphibians against pathogenic skin infections, such as the amphibian chytrid fungus (Colombo et al. 2015). A study on redback salamanders has shown that a known protective bacterium, Janthinobacterium lividum, was able to survive passage through the gut, suggesting that the gut could be a reservoir

for protective skin bacteria (Wiggins et al. 2011). We propose that this possibility should be taken into account in future assessments of the suitability of certain bacteria as probiotics to increase mucosal immunity (Woodhams et al. 2011; Bletz et al. 2013). However, the dominance of Clostridia in the observed bacterial communities and the presence of Clostridia and Synergistia among the core OTUs suggest at least partially anaerobic conditions in the intestines of both adult and larval amphibians (see also Pryor 2008), which probably differs from conditions in the skin mucosal layer. 
There are only few published data on the effect of fasting and diversity of diet on the gut bacterial communities of amphibians. Kohl et al. (2014a) found an increase of diversity after fasting in adult and subadult toads, while we observed in tadpoles of various Brazilian frogs a decrease of diversity of these communities. However, our experiment compared wild and fed with captive and fasted tadpoles and therefore could not exclude the effects of captive conditions other than fasting which can lead to drastic reductions of diversity in microbiota of the gut (Kohl et al. 2014b) and the skin (Antwis et al. 2014).

In mammals, diversity of gut bacteria increases from carnivory to omnivory to herbivory (Ley et al. 2008a; Kohl et al. 2014b) which agrees with our finding of tadpole communities being more diverse than those of adults. Our data also indicate that the tadpoles from Madagascar with most diverse diet (Chonomantis) might have the most diverse gut microbiota (Fig. 4). Such a positive correlation of diet diversity and gut microbiota diversity would however be contrary to findings in fish where specimens feeding on mixed diets had lower diversities of gut bacteria than those feeding on pure diets (Bolnick et al. 2014).

It is of relevance to note that many tadpoles are suspected to be microphagous, with bacteria probably making up part of their diet in some cases (Altig et al. 2007; Pryor 2014). If bacteria are ingested as a major dietary component, the question arises: what is actually determined by DNA-based bacterial community analyses of gut material? In human microbiome analyses, fecal material typically is thought to represent the rich colonic microbial populations. Tadpoles have a poorly differentiated stomach (Fox 1984) with a presumably limited digestive activity (Altig and McDiarmid 1999). In such larvae, the midgut (which makes up by far the largest part of the intestinal tract) can be hypothesized to contain a major proportion of DNA from bacteria ingested as part of the diet. Moreover, ingested bacteria can integrate temporarily into the transient microbial communities of their host (Derrien and van Hylckama Vlieg 2015), thus making the distinction between food-associated and "true" gut residents quite complex. However, host-associated bacteria are likely the majority of what has been sequenced because (1) the tadpole gut bacterial communities determined herein include in high proportions bacterial phyla that are common members of other gut communities, such as Firmicutes (Clostridia), Fusobacteria, or Bacteriodetes, and (2) several core OTUs that are related to bacteria known from the gut of insects; (3) because all these taxa indicate anaerobic conditions while bacteria ingested with food could be expected to be more adapted to aerobic or mixed conditions; and (4) because the potentially more aerobic groups such as Proteobacteria did not strongly decrease in proportion after fasting, an effect that would be expected for dietary bacterial matter independent of the possible added effects of captive conditions on the fasting tadpoles.
Assuming that the DNA-based approach here actually detects mostly bacteria living in the gut of tadpoles and not DNA from bacteria ingested (and digested) as food, it remains to be studied whether these communities represent intimate symbiotic associations with the host or opportunistic colonization of the tadpole gut by nonspecific environmental bacteria, as it seems to be common in many insects (Engel and Moran 2013). Our observation of multiple shared OTUs between the core gut communities of tadpoles from two entirely different geographical regions (Brazil and Madagascar) suggests that specific symbiotic relationships between microbe and host may be the case for tadpoles. Our experimental design is particularly conclusive in this case because all laboratorybased work related to the samples from Madagascar and Brazil was carried out in different laboratories, and sequencing took place at different genome centers, which fully excludes cross-sample contamination as a source for this similarity. In fact, the similarity was found despite partly different preservation conditions among Malagasy and Brazilian samples which could have altered the proportion of OTUs detected (Vlčková et al. 2012).

The shared core communities contained a series of OTUs whose particular DNA sequences so far have neither been found in other environmental samples nor in the wellstudied human microbiome, according to BLAST results. Three of these indicated a close relationship to bacteria found in insect gut samples, whereas another one had been found previously in an Asian tadpole gut sample (Chang, Ho, and Chen, unpublished) (accession numbers in Supplementary Table S5). While it is obvious that studies of bacterial communities to date are highly biased toward certain environments, and therefore BLAST searches do not provide a complete or representative picture of the distribution of an OTU in nature, our preliminary data suggest the possibility of specialized symbionts in the tadpole gut. Whether some of these might be specific for amphibians or found also in many other animal taxa requires further study.

Our data suggest that gut bacterial communities of tropical tadpoles are structured by ecological factors, such as food and aquatic environment, and by host taxonomy, the latter possibly indicating differences in gut architecture or biochemistry among amphibian groups. The combined influence of these factors agrees with the situation in other animals, such as insects (Colman et al. 2012). The data presented here indicate species-specific differences in tadpole gut bacterial composition both in the Itapé and the Ranomafana communities (Figs. 2 and 4). It will be important to understand the taxon specificity of bacteria in the amphibian gut in future investigations, and such a question can be answered by comparing gut microbiomes from tadpoles with those of other sympatric aquatic animals (such as arthropods and fish) and those of adult frogs with sympatric terrestrial animals. 
For the Madagascar species, where data on food composition and stable isotopes were also available, it was revealed that morphologically divergent tadpoles differ in their stable isotope signatures and therefore may differ in their feeding niches. The range in nitrogen isotopes was about $4 \% \delta^{15} \mathrm{~N}$, with $B$. majori having very low values and $B$. picturatus the highest values of $\delta^{15} \mathrm{~N}$. According to previous studies, this range corresponds to at least one trophic level (Post 2002; Schiesari et al. 2009). The range of $5 \%$ in $\delta^{13} \mathrm{C}$ clearly indicates that some species in this assemblage use different carbon sources than others when feeding (C4- vs. C3-originated organic carbon). On the other hand, some morphologically similar species were found to exhibit very similar isotope ratios (such as the funnel-mouth feeding Chonomantis tadpoles; Grosjean et al. 2011a), indicating a low variation in feeding ecology within such ecomorphs.

Some of the morphologically most distinct species, such as B. majori and B. picturatus, also show the most extreme values in stable isotope values. Both of these have been observed to ingest sand (Schmidt et al. 2008; Grosjean et al. 2011b), yet they differ radically in their stable isotope signatures, indicating that they might exploit unique feeding niches. The $\delta^{15} \mathrm{~N}$ value found for $B$. picturatus was higher compared to other sympatric species. This is unexpected because this species has an extreme sand-eating specialization and is not known to be predatory (Grosjean et al. 2011b). Its high trophic level relative to syntopic tadpoles might suggest that this species mainly digests miniature metazoans living in between and attached to sand grains, or pieces of carrion between sand grains, rather than bacteria. The comparatively low $\delta^{15} \mathrm{~N}$ values observed in B. majori are similar to those of Neotropical centrolenid tadpoles (Verburg et al. 2007), which have been hypothesized to be microbial feeders. Unfortunately, no gut samples suitable for microbiota analysis had been preserved for B. picturatus and B. majori.

Sample sizes in our study are too small for thorough statistical tests of a putative correlation between ecomorph, trophic niche (assessed by stable isotope data), and composition of gut bacterial communities. However, we can hypothesize that the differences observed in the gut bacterial community structures are associated with the different feeding behaviors and food substrates of these species. Exploration of the functional composition and diversity of the gut microbiota genes via metagenomics or transcriptomics should be pursued in future studies, as it would allow associations to be made between food type and functional genes of the bacteria, fungi, or protists that may aid in digestion (e.g., Gill et al. 2006). For example, tadpoles consuming more insects in their diets may have higher proportions of bacterial gene association with chitinolytic activity, as has been discussed for myrmecophagous mammals (Delsuc et al. 2014). On the other hand, algal eaters may have higher proportions of bacterial porphyranases and agarases, which are both found in seaweed-consuming humans (Hehemann et al. 2010). Furthermore, in large datasets with numerous amphibian taxa, co-occurrence and, even more important, interaction networks between food items and bacterial OTUs could be performed to elucidate which bacteria likely aide in the digestion of particular food items. Another area that was not explored in the present study is the presence and role of eukaryotic microbes, including protozoans, in the amphibian gut of tadpoles and adults. These organisms are an important component of the gut microbiota in many animals and, therefore, are an important direction for future research.

The importance of bacterial communities for eukaryotic organisms is well known, as they play a vital role in digestion, development, and immunity. Hence, developing a clearer understanding of these communities in amphibians is of significant interest. Continued field and experimental research to characterize and compare these microbiomes at a taxonomic and functional level as discussed here will deepen our understanding of these systems, which is critical for fully comprehending amphibian evolution and ecology, and improving the conservation of these fascinating animals.

Acknowledgments Work in Madagascar was made possible by a collaboration accord between the Université d'Antananarivo (Département de Biologie Animale), the Ministère de l'Environnement, des Eaux et Forêts of the Republic of Madagascar, and the Technische Universität Braunschweig. We are grateful to the Malagasy authorities for research and export permits. We are deeply indebted to Otto Larink (TU Braunschweig) for his kind help with identifying the tadpole food items. Meike Kondermann was of invaluable help with lab work. Work in Madagascar was supported by the Volkswagen Foundation to MV, JG, and RDR; by grants of the Deutsche Forschungsgemeinschaft to MV (VE247/2-1 and VE247/9-1) and JG (GL 665/1-1); and by fellowships of the Deutscher Akademischer Austauschdienst to MB and RDR. Maria J. O. Campos and Marcelo de Carvalho authorized our entry into the work area in Itapé, Rio Claro, SP, Brazil. Work in Brazil was supported by a visiting researcher grant of CAPES to MV, CFBH, and ML (88881.062205/2014-01). CFBH thanks grant \#2013/50741-7, São Paulo Research Foundation (FAPESP) and $\mathrm{CNPq}$, for a research fellowship. Experiments were approved by the Ethics Committee of UNESP Rio Claro (permit no. 36/2015).

\section{References}

Altig R, Johnston GF (1989) Guilds of anuran larvae: relationships among developmental modes, morphologies, and habitats. Herpetol Monogr 3:81-109

Altig R, McDiarmid RW (1999) Body plan: development and morphology. In: McDiarmid RW, Altig R (eds) Tadpoles. The biology of anuran larvae. The University of Chicago Press, Chicago, pp 24-51

Altig R, McDiarmid RW (2006) Descriptions and biological notes on three unusual mantellid tadpoles (Amphibia: Anura: Mantellidae) from southeastern Madagascar. Proc Biol Soc Wash 119:418-425

Altig R, Whiles MR, Taylor CL (2007) What do tadpoles really eat? Assessing the trophic status of an understudied and imperiled group of consumers in freshwater habitats. Freshw Biol 52:386-395

Antwis RE, Haworth RL, Engelmoer DJ, Ogilvy V, Fidgett AL, Preziosi RF (2014) Ex situ diet influences the bacterial community 
associated with the skin of red-eyed tree frogs (Agalychnis callidryas). PLoS One 9, e85563

Aronesty E (2011) ea-utils: Command-line tools for processing biological sequencing data. http://code.google.com/p/ea-utils. Accessed 1 Oct 2015

Aronesty E (2013) TOBioiJ: comparison of sequencing utility programs. Open Bioinforma J 7:1-8

Arribas R, Díaz-Paniagua C, Caut S, Gomez-Mestre I (2015) Stable isotopes reveal trophic partitioning and trophic plasticity of a larval amphibian guild. PLoS One 10, e0130897

Arumugam M, Raes J, Pelletier E et al (2011) Enterotypes of the human gut microbiome. Nature 473:174-180

Becker MH, Harris RN (2010) Cutaneous bacteria of the redback salamander prevent morbidity associated with a lethal disease. PLoS One 5, e10957

Becker MH, Brucker RM, Schwantes CR, Harris RN, Minibiole KPC (2009) The bacterially produced metabolite Violacein is associated with survival of amphibians infected with a lethal fungus. Appl Environ Microbiol 75(21):6635-6638

Belden LK, Hughey MC, Rebollar EA, Umile TP, Loftus SC, Burzynski EA, Minbiole KP, House LL, Jensen RV, Becker MH, Walke JB, Medina D, Ibáñez R, Harris RN (2015) Panamanian frog species host unique skin bacterial communities. Front Microbiol 6:1171

Bjorndal KA (1997) Fermentation in reptiles and amphibians. In: Mackie RI, White BA (eds) Gastrointestinal microbiology: volume 1, gastrointestinal ecosystems and fermentations. Chapman and Hall, New York, pp 199-230

Bjorndal KA, Pryor GS (2005) Effects of the nematode Gyrinicola batrachiensis on development, gut morphology, and fermentation in bullfrog tadpoles (Rana catesbeiana): a novel mutualism. J Exp Zool Part A 303:704-712

Bletz MC, Loudon AH, Becker MH, Bell SC, Woodhams DC, Minbiole KP, Harris RN (2013) Mitigating amphibian chytridiomycosis with bioaugmentation: characteristics of effective probiotics and strategies for their selection and use. Ecol Lett 16:807-820

Bloom S, Ledon-Rettig C, Infante C, Everly A, Hanken J, Nascone-Yoder N (2013) Developmental origins of a novel gut morphology in frogs. Evol Dev 15:213-223

Bokulich NA, Subramanian S, Faith JJ, Gevers D, Gordon JI, Knight R, Mills DA, Caporaso JG (2013) Quality-filtering vastly improves diversity estimates from Illumina amplicon sequencing. Nat Methods 10(1):57-59

Bolnick DI, Snowberg LK, Hirsch PE, Lauber CL, Knight R, Caporaso JG, Svanbäck R (2014) Individuals' diet diversity influences gut microbial diversity in two freshwater fish (threespine stickleback and Eurasian perch). Ecol Lett 17:979-987

Brosius J, Dull TJ, Sleeter DD, Noller HF (1981) Gene organization and primary structure of a ribosomal RNA operon from Escherichia coli. J Mol Biol 148:107-127

Brucker RM, Harris RN, Schwantes CR, Gallaher TN, Flaherty DC, Lam BA, Minbiole KPC (2008) Amphibian chemical defense: antifungal metabolites of the microsymbiont Janthinobacterium lividum on the salamander Plethodon cinereus. J Chem Ecol 34:1422-1429

Caporaso JG, Kuczynski J, Stombaugh J et al (2010) QIIME allows analysis of high-throughput community sequencing data. Nat Methods 7:335-336

Colman DR, Toolson EC, Takacs-Vesbach CD (2012) Do diet and taxonomy influence insect gut bacterial communities? Mol Ecol 21: 5124-5137

Colombo BM, Scalvenzi T, Benlamara S, Pollet N (2015) Microbiota and mucosal immunity in amphibians. Front Immunol 6:111

Delsuc F, Metcalf JL, Wegener Parfrey L, Song SJ, González A, Knight R (2014) Convergence of gut microbiomes in myrmecophagous mammals. Mol Ecol 23:1301-1317
DeNiro MJ, Epstein S (1981) Influence of diet on the distribution of nitrogen isotopes in animals. Geochim Cosmochim Acta 45: 341-351

Derrien M, van Hylckama Vlieg JET (2015) Fate, activity, and impact of ingested bacteria within the human gut microbiota. Trends Microbiol 23:354-366

Edgar RC (2010) Search and clustering orders of magnitude faster than BLAST. Bioinformatics 26:2460-2461

Edgar RC, Haas BJ, Clemente JC, Quince C, Knight R (2011) UCHIME improves sensitivity and speed of chimera detection. Bioinformatics 27:2194-2200

Engel P, Moran NA (2013) The gut microbiota of insects - diversity in structure and function. FEMS Microbiol Rev 37:699-735

Fox H (1984) Amphibian morphogenesis. Humana, New York

Gill SR, Pop M, Deboy RT, Eckburg PB, Turnbaugh PJ, Samuel BS, Gordon JI, Relman DA, Fraser-Liggett CM, Nelson KE (2006) Metagenomic analysis of the human distal gut microbiome. Science 312:1355-1359

Grosjean S, Strauß A, Glos J, Randrianiaina R-D, Ohler A, Vences M (2011a) Morphological and ecological uniformity in the funnelmouthed tadpoles of Malagasy litter frogs, subgenus Chonomantis. Zool J Linnean Soc 162:149-183

Grosjean S, Randrianiaina R-D, Strauß A, Vences M (2011b) Sand-eating tadpoles in Madagascar: morphology and ecology of the unique larvae of the treefrog Boophis picturatus. Salamandra 47:63-76

Harris RN, James TY, Lauer A, Simon MA, Patel A (2006) Amphibian pathogen Batrachochytrium dendrobatidis is inhibited by the cutaneous bacteria of amphibian species. EcoHealth 3:53-56

Harris RN, Brucker RM, Walke JB et al (2009) Skin microbes on frogs prevent morbidity and mortality caused by a lethal skin fungus. ISME J 3:818-824

Hehemann JH, Correc G, Barbeyron T, Helbert W, Czjzek M, Michel G (2010) Transfer of carbohydrate-active enzymes from marine bacteria to Japanese gut microbiota. Nature 464:908-912

Inger RF (1986) Diets of tadpoles living in a Borneo rain forest. Alytes 5: 153-164

Jani AJ, Briggs CJ (2014) The pathogen Batrachochytrium dendrobatidis disturbs the frog skin microbiome during a natural epidemic and experimental infection. Proc Natl Acad Sci U S A 111:E5049-5058

Kohl KD, Cary TL, Karasov WH, Dearing MD (2013) Restructuring of the amphibian gut microbiota through metamorphosis. Environ Microbiol Rep 5:899-903

Kohl KD, Amaya J, Passement CA, Dearing MD, McCue MD (2014a) Unique and shared responses of the gut microbiota to prolonged fasting: a comparative study across five classes of vertebrate hosts. FEMS Microbiol Ecol 90:883-894

Kohl KD, Skopec MM, Dearing MD (2014b) Captivity results in disparate loss of gut microbial diversity in closely related hosts. Conserv Phys 2:cou009

Kozich JJ, Westcott SL, Baxter NT, Highlander SK, Schloss PD (2013) Development of a dual-index sequencing strategy and curation pipeline for analyzing amplicon sequence data on the MiSeq Illumina sequencing platform. Appl Environ Microbiol 79:5112-5120

Kueneman JG, Wegener Parfrey L, Woodhams DC, Archer HM, Knight R, McKenzie VJ (2014) The amphibian skin-associated microbiome across species, space and life history stages. Mol Ecol 23:1238-1250

Kueneman JG, Woodhams DC, Van Treuren W, Archer HM, Knight R, McKenzie VJ (2016) Inhibitory bacteria reduce fungi on early life stages of endangered Colorado boreal toads (Anaxyrus boreas). ISME J. doi:10.1038/ismej.2015.168

Lauer A, Simon MA, Banning JL, Andre E, Duncan K, Harris RN (2007) Common cutaneous bacteria from the eastern red-backed salamander can inhibit pathogenic fungi. Copeia 3:630-640 
Lauer A, Simon MA, Banning JL, Lam BA, Harris RN (2008) Diversity of cutaneous bacteria with antifungal activity isolated from female four-toed salamanders. ISME J 2:145-157

Layman CA, Quattrochi JP, Peyer CM, Allgeier JE (2007a) Niche width collapse in a resilient top predator following ecosystem fragmentation. Ecol Lett 10:937-944

Layman CA, Arrington DA, Montana CG, Post DM (2007b) Can stable isotope ratios provide for community-wide measures of trophic structure? Ecology 88:42-48

Ley RE, Hamady M, Lozupone C, Turnbaugh PJ, Ramey RR, Bircher JS, Schlegel ML, Tucker TA, Schrenzel MD, Knight R, Gordon JI (2008a) Evolution of mammals and their gut microbes. Science 320:1647-1651

Ley RE, Lozupone CA, Hamady M, Knight R, Gordon JI (2008b) Worlds within worlds: evolution of the vertebrate gut microbiota. Nat Rev Microbiol 6:776-788

Loudon AH, Woodhams DC, Parfrey LW, Archer H, Knight R, McKenzie V, Harris RN (2014) Microbial community dynamics and effect of environmental microbial reservoirs on red-backed salamanders (Plethodon cinereus). ISME J 8:830-840

Lozupone C, Knight R (2005) UniFrac: a new phylogenetic method for comparing microbial communities. Appl Environ Microbiol 71: $8228-8235$

McFall-Ngai M, Hadfield MG, Bosch TC et al (2013) Animals in a bacterial world, a new imperative for the life sciences. Proc Natl Acad Sci U S A 110:3229-3236

McKenzie VJ, Bowers RM, Fierer N, Knight R, Lauber CL (2012) Cohabiting amphibian species harbor unique skin bacterial communities in wild populations. ISME J 6:588-596

Oliveros JC (2015) Venny. An interactive tool for comparing lists with Venn's diagrams. http://bioinfogp.cnb.csic.es/tools/venny/index. html. Accessed 1 Oct 2015

Palm NW, de Zoete MR, Flavell RA (2015) Immune-microbiota interactions in health and disease. Clin Immunol 159(2):122-127

Peterson BJ, Fry B (1987) Stable isotopes in ecosystem studies. Annu Rev Ecol Syst 18:293-320

Post DM (2002) Using stable isotopes to estimate trophic position: models, methods, and assumptions. Ecology 83:703-718

Price MN, Dehal PS, Arkin AP (2010) FastTree 2-approximately maximum-likelihood trees for large alignments. PLoS One 5, e9490

Pryor GS (2008) Anaerobic bacteria isolated from the gastrointestinal tracts of bullfrog tadpoles (Rana catesbeiana). Herpetol Conserv Biol 3:176-181

Pryor GS (2014) Tadpole nutritional ecology and digestive physiology: implications for captive rearing of larval anurans. Zool Biol 33:502-507

Qiu X, Wu L, Huang H, McDonel PE, Palumbo AV, Tiedje JM, Zhou J (2001) Evaluation of PCR-generated chimeras, mutations, and heteroduplexes with 16S rRNA gene-based cloning. Appl Environ Microbiol 67(2):880-887

Rossa-Ferres DC, Jim J, Fonseca MG (2004) Diets of tadpoles from a temporary pond in southeastern Brazil (Amphibia, Anura). Rev Bras Zool 21:745-754

Schiesari L, Werner EE, Kling GW (2009) Carnivory and resource-based niche differentiation in anuran larvae: implications for food web and experimental ecology. Freshw Biol 54:572-586
Schmidt H, Strauß A, Reeve E, Letz A, Ludewig AK, Neb D, Pluschzick R, Randrianiaina RD, Reckwell D, Schröder S, Wesolowski A, Vences M (2008) Descriptions of the remarkable tadpoles of three treefrog species, genus Boophis, from Madagascar. Herpetol Notes $1: 49-57$

Segata N, Izard J, Walron L, Gevers D, Miropolsky L, Garrett W, Huttenhower C (2011) Metagenomic biomarker discovery and explanation. Genome Biol 12:R60. doi:10.1186/gb-2011-12-6-r60

Strauß A, Reeve E, Randrianiaina RD, Vences M, Glos J (2010) The world's richest tadpole communities show functional redundancy and low functional diversity: ecological data on Madagascar's stream-dwelling amphibian larvae. BMC Ecol 10:12. doi:10.1186/ 1472-6785-10-12

Strauß A, Randrianiaina RD, Vences M, Glos J (2013) Species distribution and assembly patterns of frog larvae in rainforest streams of Madagascar. Hydrobiol 702:27-43

Toloza EM, Diamond JM (1990) Ontogenetic development of nutrient transporters in bullfrog intestine. Am J Physiol 258:G760-769

Tuddenham S, Sears CL (2015) The intestinal microbiome and health. Curr Opin Infect Dis 28(5):464-470

Vences M, Gehara M, Köhler J, Glaw F (2012) Description of a new Malagasy treefrog (Boophis) occurring syntopically with its sister species, and a plea for studies on non-allopatric speciation in tropical amphibians. Amphibia-Reptilia 33:503-520

Verburg P, Kilham SS, Pringle CM, Lips KR, Drake DL (2007) A stable isotope study of a neotropical stream food web prior to the extirpation of its large amphibian community. J Trop Ecol 23:643-653

Viertel B, Richter S (1999) Anatomy: viscera and endocrines. In: McDiarmid RW, Altig R (eds) Tadpoles: the biology of anuran larvae. University of Chicago Press, Chicago, pp 92-148

Vlčková K, Mrázek J, Kopečný J, Petrželková KJ (2012) Evaluation of different storage methods to characterize the fecal bacterial communities of captive western lowland gorillas (Gorilla gorilla gorilla). $\mathrm{J}$ Microbiol Methods 91:45-51

Wang Q, Garrity GM, Tiedje JM, Cole JR (2007) Naive Bayesian classifier for rapid assignment of rRNA sequences into the new bacterial taxonomy. Appl Environ Microbiol 73:5261-5267

Whiles MR, Lips KR, Pringle CM et al (2006) The effects of amphibian population declines on the structure and function of Neotropical stream ecosystems. Front Ecol Environ 4:27-34

Wiggins PJ, Smith JM, Harris RN, Minbiole KPC (2011) Gut of redbacked salamanders (Plethodon cinereus) may serve as a reservoir for an antifungal cutaneous bacterium. J Herpetol 45:329-332

Woodhams DC, Vredenburg VT, Simon M, Billheimer D, Shakhtour B, Shyr Y, Briggs CJ, Rollins-Smith LA, Harris RN (2007) Symbiotic bacteria contribute to innate immune defenses of the threatened mountain yellow-legged frog, Rana muscosa. Biol Conserv 138: 390-398

Woodhams DC, Bosch J, Briggs CJ et al (2011) Mitigating amphibian disease: strategies to maintain wild populations and control chytridiomycosis. Front Zool 8:8

Zina J, Ennser J, Pinheiro SCP, Haddad CFB, Toledo LF (2007) Taxocenose de anuros de uma mata semidecídua do interior do Estado de São Paulo e comparações com outras taxocenoses do Estado, sudeste do Brasil. Biota Neotropical 7:1-9 